\section{Bioética social y vulneración de derechos frente a la insolvencia patrimonial}

\section{Bernal, M P}

Abogada, docente/investigadora UNMDP. Docente de "Derecho Consitucional" UCAECE y de "Derecho Concursal" UNMDP. Miembro Comité de Bioética Hospitales Interzonales Materno Infantil "Tetamanti" $y$ General de Agudos "Alende" de Mar del Plata. marcelapaulinabernal@gmail.com

PALAVRAS-CHAVE: bioética social-insolvenciavulnerabilidad-Argentina

Introducción: Desde la bioética social, y desde la perspectiva de la Declaración Universal de Bioética y DHDH UNESCO 2005 (1), se reflexiona sobre el impacto de la insolvencia patrimonial respecto de las personas más vulnerables como violación de sus DHDH y del principio de no maleficencia, en un contexto atravesado por la desigualdad, desocupación, ruptura de la cadena de pagos y contracción económica de Argentina. Método: Se ha utilizado la indagación y análisis bibliográficos y la observación objetivada de interpretación y análisis del contexto a partir de la práctica docente en la asignatura "Derecho Concursal". Se parte de la bioética con enfoque del "desarrollo humano" siguiendo a Vidal (2013) (2) y se la vincula con la protección del derecho concursal vigente. Resultados: Esta normativa es insuficiente para la tutela de los consumidores sobreendeudados, los trabajadores y sus familias, las pequeñas y medianas empresas, los proveedores, el derecho a la salud, el derecho a una vivienda digna y el interés general. Desde la humanización y constitucionalización del derecho privado deben revisarse los mecanismos de la ley de concursos y quiebras que tutelan principalmente el crédito y el patrimonio, con una cosmovisión mercantilista. En la balanza deben priorizarse los derechos humanos a una vida y vivienda dignas, a la salud y al trabajo por sobre cualquier otro interés. En este sentido, el derecho concursal, desde una mirada de la bioética social, debe respetar los tratados de derechos humanos y debe tener una visión centrada en el principio pro homine. No obstante, no afronta adecuadamente la situación de los empleados, jubilados, amas de casa, profesionales y de otras personas, como así tampoco la problemática del contexto familiar dañado con el desempleo que provoca la insolvencia patrimonial. Menos aún, contempla la situación de los consumidores y usuarios de productos y servicios. Los consumidores son inducidos a la compra compulsiva. En estas relaciones de consumo, los sujetos no están en igualdad de condiciones. Frente a un proveedor del bien o servicio, altamente profesionalizado, se encuentra un consumidor débil. El sistema concursal no ofrece actualmente una respuesta adecuada para el caso de su sobreendeudamiento. Resulta necesario así un régimen diferencial de carácter tuitivo frente a la violación de los principios bioéticos de vulnerabilidad y dignidad desencadenada ante una crisis patrimonial, en cumplimiento de la Declaración Universal de Bioética y DHDH UNESCO 2005. Constituye un deber del Estado hacerse cargo de esta cuenta pendiente mediante acciones positivas, en cumplimiento también de nuestra Carta Magna. Conclusión En base a lo expuesto, se considera que en las condiciones existentes el impacto que provoca la insolvencia respecto a las personas más vulnerables atenta contra el concepto de salud de las mismas, que debe incluir también la posibilidad de tener un "proyecto de vida digno", desde una bioética contextualizada a América Latina, siguiendo el enfoque planteado.

\section{REFERÊNCIAS:}

(1) UNESCO. Declaración Universal de Bioética y Derechos Humanos.

(2)VIDAL S. Bioética y desarrollo humano: una visión desde América Latina. (2013) 